\title{
Publisher Correction: Inside quantum black boxes
}

\section{Vedran Dunjko (1)}

Correction to: Nature Physics https://doi.org/10.1038/s41567-021-01246-8, published online 24 May 2021.

In the version of this News \& Views article originally published, the second arrow in Fig. 1 was mistakenly labelled 'Measurement', but it should have been 'Post-processing. The error has been corrected in all versions of the article.

Published online: 3 June 2021

https://doi.org/10.1038/s41567-021-01284-2

(c) Springer Nature Limited 2021

\section{Author Correction: Absolute ${ }^{13} \mathrm{C} /{ }^{12} \mathrm{C}$ isotope amount ratio for Vienna PeeDee Belemnite from infrared absorption spectroscopy}

\author{
Adam J. Fleisher (D), Hongming Yi D, Abneesh Srivastava, Oleg L. Polyansky D, Nikolai F. Zobov and Joseph T. Hodges \\ Correction to: Nature Physics https://doi.org/10.1038/s41567-021-01226-y, published online 26 April 2021.
}

In the version of this Letter originally published, in Fig. $2 \mathrm{a}$, the $y$-axis label ' $R\left({ }^{13} \mathrm{C} /{ }^{12} \mathrm{C}\right)_{\mathrm{VPDB}}(\%)$ ' was incorrect and should have been ${ }^{\prime} R\left({ }^{13} \mathrm{C} /{ }^{12} \mathrm{C}\right)_{\text {sample }}(\%)$ '. Furthermore, the realization of a $\delta^{13} \mathrm{C}$ value for the reference sample of North American Continental Air, NIST Standard Reference Material 1720, was mistakenly attributed to the World Meteorological Organization (WMO) Global Atmosphere Watch Central Calibration Laboratory at the National Oceanic and Atmospheric Administration (NOAA), but should have been attributed to the Institute of Arctic and Alpine Research (INSTAAR), part of the University of Colorado Boulder; thus, the sentences beginning "These spectra were measured using..." and "The NIST Standard Reference Material 1720..." have been amended accordingly, as has the footnote for Supplementary Table S4. All versions of the Letter have been corrected and the Supplementary Information file replaced.

Published online: 15 June 2021

https://doi.org/10.1038/s41567-021-01293-1

This is a U.S. government work and not under copyright protection in the U.S.; foreign copyright protection may apply 2021

\section{Author Correction: Plasma optics: Reflections off a relativistic mirror \\ Laszlo Veisz (D) \\ Correction to: Nature Physics https://doi.org/10.1038/s41567-021-01259-3, published online 3 June 2021.}

In the version of this News \& Views article originally published online, the reference originally cited in the sentence beginning "An ultra-intense laser pulse reflected from..." was incorrect; the correct reference should have been to "Vincenti, H. Phys. Rev. Lett. 123, 105001 (2019)", which wasn't originally included and has now been added as ref. 6. Subsequent references have been renumbered. In addition, in the sentence beginning "This may enable approaching the Schwinger limit...", refs. 7 and 8 should have been cited instead of just ref. 7. All versions of the article have been amended.

Published online: 25 June 2021

https://doi.org/10.1038/s41567-021-01303-2

(c) Springer Nature Limited 2021 